\title{
BMJ Open Clitoral surgery on minors: an interview study with clinical experts of differences of sex development
}

\author{
Lih-Mei Liao, ${ }^{1}$ Peter Hegarty, ${ }^{2}$ Sarah Creighton, ${ }^{1}$ Tove Lundberg, ${ }^{3}$ Katrina Roen ${ }^{\bullet, 5}$
}

To cite: Liao L-M, Hegarty P, Creighton S, et al. Clitoral surgery on minors: an interview study with clinical experts of differences of sex development. BMJ Open 2019:9:e025821. doi:10.1136/ bmjopen-2018-025821

- Prepublication history and additional material is published online only. To view, please visit the journal online (http://dx.doi. org/10.1136/bmjopen-2018025821).

Received 10 August 2018 Revised 20 March 2019 Accepted 16 May 2019

\section{Check for updates}

(C) Author(s) (or their employer(s)) 2019. Re-use permitted under CC BY-NC. No commercial re-use. See rights and permissions. Published by BMJ.

${ }^{1}$ Women's Health Division, University College London Hospitals NHS Foundation Trust, London, UK

${ }^{2}$ School of Psychology, University of Surrey, Guildford, UK

${ }^{3}$ Department of Psychology, Lund University, Lund, Sweden ${ }^{4}$ School of Social Sciences, University of Waikato, Hamilton, New Zealand

${ }^{5}$ Department of Psychology, University of Oslo, Oslo, Norway

Correspondence to

Dr Katrina Roen

kroen@waikato.ac.nz

\begin{abstract}
Objectives Clitoral surgery on minors diagnosed with differences of sex development is increasingly positioned as a violation of human rights. This qualitative study identified how health professionals (HPs) navigate the contentious issues as they offer care to affected families. Design Qualitative analysis of audio-recorded semistructured interviews with HPs. All of the interviews were transcribed verbatim for theoretical thematic analysis.

Setting Twelve specialist multidisciplinary care centres for children, adolescents and adults diagnosed with a genetic condition associated with differences of sex development.
\end{abstract}

Participants Thirty-two medical, surgical, psychological and nursing professionals and clinical scientists in 12 specialist centres in Britain and Sweden formed the interview sample.

Results All interviewees were aware of the controversial nature of clitoral surgery and perceived themselves and their teams as non-interventionist compared with other teams. Data analyses highlighted four strategies that the interviewees used to navigate their complex tasks: (1) engaging with new thinking, (2) holding on to historical assumptions, (3) reducing the burden of dilemmas and (4) being flexible. In response to recent reports and debates that challenge clitoral surgery on minors, HPs had revised some of their opinions. However, they struggled to reconcile their new knowledge with the incumbent norms in favour of intervention as they counsel care users with variable reactions and expectations. The flexible approach taken may reflect compromise, but the interviewees were often trapped by the contradictory values and assumptions.

Conclusions If the pathology-based vocabularies and narratives about genital diversity could be modified, and normative assumptions are questioned more often, clinicians may be more adept at integrating their new knowledge into a more coherent model of care to address the psychosocial concerns that genital surgery purports to overcome.

\section{INTRODUCTION}

Terms such as intersex, disorders or differences of sex development and diverse sex development $(\mathrm{DSD})^{1}$ are used to refer to a group of genetic conditions where the combination of chromosomal, gonadal and genital
Strengths and limitations of this study

This is the largest interview study of European diverse sex development (DSD) professionals to date.

- The analytic method used enables identification of strategies of health professionals (HPs) for managing a persistent dilemma in relation to DSD healthcare.

- There could be selection bias in the event that only those HPs questioning elective surgical intervention volunteered to participate.

- The implications of this study speak directly to the latest consensus about treatment practices.

sex characteristics does not map clearly onto the social categories of female or male. Some DSD conditions are associated with so-called ambiguous genitalia, such as when the clitoris-penis is deemed too large or too small, depending on the gender assigned to the child.

Gender assignment in these scenarios is complex and taxing. It takes account of the (preferably genetic) diagnosis, reproductive and sex anatomy, surgical options, fertility potential, exposure to prenatal androgens and parental preferences. ${ }^{2}{ }^{3}$ From the late 1950 s, in an era when the clitoris was not labelled as part of the human body in editions of Grey's Anatomy, removal of all or part of the clitoris became a standard intervention for female-assigned children with ambiguous genitalia. Techniques have evolved from clitoredectomy (amputation of the clitoris) to clitoral recession (pleating together the erectile tissue to shorten the clitoris) and clitoral reduction (removal of the erectile tissue while attempting to preserve the nerve and blood vessels). ${ }^{4}$

Infants and children cannot consent to surgery. Parental consent is usually predicated on the assumption that surgery will stabilise gender identity, prevent any negative psychosocial consequences of growing up with a larger clitoris and offer the adult normality in sexuality and relationships. ${ }^{5-8}$ 
Thus far, providers of childhood feminising genital surgery have reported only short-term outcomes and not the intended lifelong benefits. ${ }^{9}$ Attempts to review surgical outcomes are limited by small sample sizes, diverse surgical techniques and high attrition rates. Surgical evidence is further limited by the subjective nature of any evaluation of genital appearance. Without longitudinal evidence, it remains a leap of faith to extrapolate from childhood outcomes that satisfy paediatricians to outcomes that satisfy the postpubertal, sexually active adults who underwent childhood clitoral surgery.

In a landmark report based on 44 women who had undergone a 'one-stage' childhood feminising genitoplasty, almost all of the participants had already undergone multiple genital operations and were still in need of further surgery. ${ }^{10}$ Subsequent research has identified an association between clitoral surgery and inorgasmia ${ }^{11}$ and loss of clitoral sensitivity. ${ }^{12}$ In the most recent study of its kind, many adults expressed dissatisfaction with outcomes of their childhood surgery. ${ }^{13}$ These reports suggest that clitoral surgery is not achieving the intended long-term psychosocial and psychosexual goals. Furthermore, trauma and shame from multiple genital examinations and operations are a key theme in survivor stories. ${ }^{14}$

The 2006 Consensus Statement on Management of Intersex Disorders acknowledged that surgery can harm and that risks of no surgery, which vary by condition, had been overstated. ${ }^{2}$ For example, the consensus statement clarified that medical knowledge provided only limited insight into gender identity development and that there was no evidence that surgery benefitted family relationships. Experts recommended that clitoral surgery be limited to cases of 'severe virilisation', a restriction subsequently challenged by paediatric surgeons confident in their ability to overcome the identified problems with new operative techniques. ${ }^{1516}$ In a project aimed to estimate the impact of the consensus statement, half of the participating European DSD teams self-reported a reduction in clitoral surgery. ${ }^{17}$ However, actual National Health Service data in the UK indicated that the prevalence of clitoral surgery had not changed. ${ }^{4}$ In a recent multicentre study in the USA with parents of female-assigned and male-assigned children with genital differences, almost all of the parents in the study sample opted for their child to have genitopasty. ${ }^{18}$

Meanwhile, intersex activists have made significant advances in positioning childhood surgery as a human rights violation. ${ }^{19}$ In 2013, the Council of Europe called on its member states to 'ensure that no-one is subjected to unnecessary medical or surgical treatment that is cosmetic rather than vital for health during infancy or childhood'. ${ }^{20}$ In the same year, the UN Special Rapporteur on Torture called on nation states to repeal laws allowing 'forced gender-normalising surgeries'. ${ }^{21}$ From April 2015, parents in Malta may consent to 'any sex assignment treatment and/or surgical intervention on the sex characteristics of a minor' only in 'exceptional circumstances' and must not be 'driven by social factors' ${ }^{22}$ In the same year, the European Union Fundamental Rights Agency recommended that member states 'avoid non-consensual sex normalising medical treatments on intersex people'. ${ }^{23}$ These developments follow ongoing critiques of medical intervention on intersex bodies published in academic social science literature, summarised in a recent review. ${ }^{24}$

Normalising clitoral surgery on minors is contentious, and health professionals (HPs) have the difficult task of helping parents decide. The current study asks: how do HPs specialising in this work currently negotiate the dilemmas surrounding clitoral surgery on minors?

\section{METHODS}

The current study is part of a larger project that involved talking to clinicians, affected young people, parents and general population samples about variations in sex development in Scotland, England, Norway and Sweden (SENS). The SENS project includes the largest interview study of European DSD professionals to date. It draws from critical psychological theory and focuses on how participants make sense of clinical practice.

The current study is based on qualitative semistructured interviews with HPs who were sampled internationally to provide a large enough group to offer anonymity. The 32 participants were recruited via email invitation from 12 hospitals in Britain and Sweden. They were recruited to the study via purposive snowball sampling. ${ }^{25}$ All were members of or affiliated to multidisciplinary teams for children, adolescents and adults with DSD. Most were highly clinically experienced in this field and many were also research active. They were: 13 surgical specialists (gynaecologists, urologists and paediatric surgeons), 9 non-surgical specialists (endocrinologists and geneticists), 7 psychologists and 3 nurse specialists. All gave fully informed written consent to participate.

An academic psychologist (last author) not involved in care provision and not known to most of the participants carried out the semistructured interviews, which were guided by open questions (as shown in online supplementary file 1) that addressed clitoral surgery specifically, as well as other surgical, hormonal and psychological interventions in relation to sex development. The interviews were audio-recorded and transcribed verbatim by a professional transcriber and have been anonymised and stored securely in accordance with ethical requirements. Numbers in brackets (preceded by $\mathrm{P}$ ) in the Results section refer to the participants' anonymisation code. Unpublished data are not available to anyone outside the research team due to the sensitivity of the transcripts.

The data have been analysed using theoretical thematic analysis. ${ }^{26}$ First, the transcripts were coded according to types of clinical intervention and professional roles. Then, data coded as focusing on clitoral enlargement and clitoral surgery underwent further analysis. Existing literature was consulted to identify themes that resonated with the present analysis, and theoretical understandings from critical psychology were drawn on to inform the 
analysis and interpretation. The themes that emerged out of this analysis centre on how HPs manage the issue of clitoral surgery.

\section{Public and patient involvement}

This study involves HPs rather than patients. A full account of the consultation process appears at the end of this article.

\section{RESULTS}

The interviewees consistently referred to clitoral surgery as 'the big debate' or 'one big grey area'. All of those who mentioned the stance taken by their team claimed a 'conservative' approach (P15) and described themselves and their colleagues as 'a lot more restrictive' (P22), being 'quite hands off' (P21) and 'much happier to not perform surgery' (P32). The consistency suggests a dynamic of pluralistic ignorance; all teams articulated reasons to reject the incumbent norm of continuing the practice of clitoral surgery but, in the absence of clear data on rates of surgery, they believed that other teams were more in favour of it than themselves. Our analysis suggests that the HPs managed the conflicting views on surgery by deploying four overlapping strategies: (1) engaging with new thinking, (2) holding on to historical assumptions, (3) reducing the burden of dilemma and (4) being flexible. These strategies are discussed in the context of relevant literatures.

\section{Engaging with new thinking}

Some of the data show how HPs engaged with new thinking, for example, when participants mentioned scientific reports that challenge the validity of childhood clitoral surgery. One paediatric endocrinologist said, 'If you had asked me fifteen years ago I would have said that [it] may be important to do surgery to prevent urinary infections and so on but then the follow-up shows that is not really an issue...' (P14). This HP went on to say:

with time I have become more hesitant erm... to let children have surgery and I think also after we have had this $[\ldots]$ follow up of the CAH [congenital adrenal hyperplasia] women I think also I am more hesitant so we have a number of CAH girls now that are not erm... that have not been through surgery...

Bioethical discussions emphasise the rights of the child to an open future in which their cognitive and emotional capacities could be taken into account as they become more involved in decision-making over time. ${ }^{27} 28$ The influences of conversations about children's right to decide for themselves (later) were evident:

...I don't think that [parental consent to surgery] is um, appropriate anymore. I think the patient should be able to um, decide for herself later on in life. (P24)

Another type of new knowledge, that which has come from collaborative, interdisciplinary efforts by advocates, ethicists and clinicians to destigmatise genital variations when conversing with parents, ${ }^{29}$ was much less visible in the present data. One HP did report talking to parents about their newborn as a 'beautiful baby' whom the team would like to get to know better in order to assist the family (P34), but the use of a more socially inclusive language was, on the whole, rare in the transcripts.

\section{Holding on to historical assumptions}

Concerns about the psychosocial impact of anatomical differences are realistic, and it is the responsibility of DSD teams to support patients and families to address their concerns. Much of the dataset demonstrates how HPs were familiar with the idea of normalising surgery as an effective solution to address potential psychosocial difficulties. However, the idea that surgery would normalise anatomy and therefore overcome the anticipated difficulties in peer relations is an assumption that has not been evidenced. Nevertheless, the interviewees repeatedly cited such assumptions as the question of clitoral surgery came up in interview:

Well I suppose it's... normalising the appearance so that they feel more normal erm... so that might mean that it's easier for them in a social si- you know swimming costumes that sort of thing so they don't look unusual. (P21)

While the HPs had not come across children being bullied or rejected on account of untreated genital differences, for example, a psychologist said, 'I have not necessarily experienced that first hand to know if families do experience that', (P40) unmanageable negative psychosocial consequences were generally assumed. It was also suggested that a more normative genital appearance would help the family to accept the child. For example, a urologist said, 'the family needs to have the surgery in order to bond with the child' (P32). Clitoral reduction was acknowledged by this HP as being 'more for [the parents] than necessarily for the child' - the kind of reasoning that is strongly discouraged by human rights policies. ${ }^{22}$ Furthermore, a feasibility study involving parents who deferred clitoral surgery for their female-assigned children reported no undue psychosocial concerns about clitoral enlargement, at least in childhood, provided appropriate medical and psychological care were in place. $^{30}$

In the earliest interview study with DSD clinicians on record, ${ }^{31}$ Kessler made the point that clinicians consciously and non-consciously drew on their personal values and preferences as they interpreted the needs of children and their parents. This observation could also be identified in the current data. For example, a nurse specialist said, 'maybe if I had a child of my own and they, and they had a very ... large clitoromegaly, I, I, I might want them to have surgery ... but that's my own personal, you know?' (P35).

The consensus statement acknowledged the absence of evidence that clitoral surgery succeeded in normalising 
anatomy, identity and relationships. ${ }^{2}$ Rather, research shows that parents feel inhibited about discussing genital differences with their child and talking about the genitoplasty to which they had consented..$^{32}{ }^{33}$ Research also shows that genital surgery is an aspect of DSD that affected adults least often talk about with others. ${ }^{34}$ Surgery could therefore introduce additional stigma for individuals and families to overcome. While the interviewees understood early surgery to be controversial because it compromised the rights of the child, they rarely referenced other factors in the controversy, such as the lack of evidence for its intended psychosocial benefits and the potential for it to cause harm.

\section{Reducing the burden of dilemma}

The data suggest that many HPs tackled the surgery dilemma by separating the easier decisions from the more difficult ones. Three factors appear to make clitoral surgery less dilemmatic: patient choice, clitoral size and surgical skills.

Clitoral surgery was considered unproblematic if the patient were to express a wish for it, as one participant said, 'one constantly has to consider the patients' needs and wishes...' (P22).

The second factor considered to lessen the dilemma was the severity of clitoral enlargement. According to the consensus statement, clitoral surgery should be reserved for cases of severe virilisation. ${ }^{2}$ Some HPs would, for example, say to the parents of a girl with a mildly enlarged clitoris, 'No, this is not a surgical option' but would perform clitoral surgery if the child were 'definitely being raised as female for very good reasons' and had 'a very large phallus' (P29). Likewise, another HP said, 'it is not necessary to do anything at all' for girls presenting 'a mild phenotype' (P16), yet another said, 'it's not so easy to be raised as a girl and have a penis' (P25).

Some interviewees suggested, however, that size did not map neatly onto surgical decision. They acknowledged that parental preference 'doesn't always reflect the degree of abnormality' (P21), so much so that 'you cannot predict which family will want [surgery] and which ones are not going to want it'. (P32) According to some HPs, parents of children with larger clitorises varied 'enormously' in attitude, with some parents being keen to accept surgery and others just as keen to avoid it. According to the interviewees, patients also seem to be highly variable in their responses to a bigger clitoris. For example, contrary to the HP above who felt that it was 'not easy to be raised as a girl and have a penis', the gynaecologist below reflected on exactly such a girl for whom large clitoral size was a non-problem:

However, [laughs] she's not that bothered by it [laughs] and it's not giving her any trouble... so although her phallus looks big to us... we haven't said to her, you know, 'You've got a big clitoris there,' but we're interested in it. (P20)
It is recognised that some individuals who were surgically feminised in childhood subsequently reassign themselves as male. ${ }^{3}$ Furthermore, physicians have reported successful male assignment of 46,XX (XX refers to chromosomes) children with severely virilised genitals ${ }^{35}$ and questioned the 'dogma' of female assignment that is typical for these children. Such realities render surgery for severe virilisation no less dilemmatic than for mild virilisation. Despite these known observations, a psychologist in the current study struggled for 17 seconds to express doubt about the necessity of clitoral surgery:

Eh... [silence 17s] I mean... the clitoris could be... when it comes to function... as big... as almost a normal penis... but... ehm... but I still think that... ehm... I'm now thinking, is there a medical... indication... for operating that big clitoris? (P37)

The data suggest that, in the instance of significant clitoral enlargement, some HPs specialising in this area can sometimes forget that clitoral surgery is not being done to address biomedical concerns. It is this very point that makes it dilemmatic.

A third strategy that participants used to reduce the burden of dilemma involves maintaining a high level of professional confidence in preserving clitoral sensitivity while normalising genital appearance. A gynaecologist who worked with a plastic surgeon described the care that they would take to 'disguise' the clitoris by building up the hood without disturbing the blood and nerve supply and not 'getting priapism or getting [the clitoris] completely insensate' (P20). Another gynaecologist referred to 'elaborate techniques' that preserve function and sensation 'to the highest degree' (P22). Direct references to the risk of severing the diffuse nerve supply around the clitoris ${ }^{36}$ and the association between clitoral surgery and impaired genital sensitivity ${ }^{12}$ were rare in the transcripts. Some adults who had been recipients of childhood clitoral surgery have challenged the notion that sensation could be reliably preserved or that better surgery was the answer to genital variations. ${ }^{37}$ These perspectives were likewise not prominent in the present data.

In the clinical literature, poor results are often attributed to older techniques and deemed no longer relevant, and optimism is maintained via confidence in new techniques. ${ }^{9}$ As a gynaecologist said, surgeons 'all use different methods so it is really difficult to compare' (P21). Confusion around how to interpret the changing surgical literature was evident in the interviews. There was, for example, a tendency to view poor outcomes as unique to other teams.

We had a paediatric surgeon who worked here who did really really nice repairs and some of his patients that have come through now... actually I think the results were good... I know the [name of a different hospital] experience is that most of the results are pretty bad and some of them don't look good at all. (P21) 
These perceptions could lead to a situation whereby parents' and patients' decisions are not being guided by realistic risk information. There are many examples throughout the data of participants using these strategies to reduce the burden of the dilemma around clitoral surgery. Another common approach was to try to be flexible rather than to take a clear and principled stand.

\section{Being flexible}

Given the uncertainties, a flexible approach might seem reasonable. However, an unprincipled approach could trap HPs in scenarios of paradoxical intentions. In the example excerpt below, the paediatric endocrinologist was clearly considering the child's rights but was equally compelled to satisfy the wishes of the parents:

Personally I, I don't tend to encourage any surgery. Because I, I really strongly believe that it should be the patient choice... but if the family will point it out, then I will have an open discussion and I will to refer to people with lot of expertise. (P18)

Clinicians have observed that some parents strongly disagree with the idea that children should decide about surgery for themselves. ${ }^{6}$ Therefore, what happens if a parent were to insist on operating on a small child whose clitoris is insignificantly enlarged? A urologist referred to just such a dilemma:

And then I've seen, um, little girls with a clitoris that's very mildly enlarged and it causes the family great concern and you counsel them strongly not to have surgery and they still, 'No we want it.' So that's a more difficult one. (P32)

Researchers have observed that to some parents, surgery is so obvious that it did not require decision-making. ${ }^{5} 38$ Some parents have indicated that they would consent to surgery even if it would reduce genital sensitivity. ${ }^{6}$ Our research participants have struggled with families who are apparently 'adamant that they want something done' (P15). A geneticist made the observation that some parents did not comply with their child's steroid medication and, when warned about potential clitoral regrowth, a parent apparently said, '.. we can always go back to the surgeons for more surgery...' (P11). One urologist said 'we are performing surgery at the parent's request ... which I have some difficulty with' (P32). The absence of a principled framework would make it difficult to respond to such challenging clinical scenarios with clarity and consistency.

\section{DISCUSSION}

This study shows how HPs specialising in DSD may understand childhood clitoral surgery as controversial yet fall back on spurious claims about intended but unevidenced psychosocial benefits of such surgery. It appears that some HPs forget that clitoral surgery is not done for medical reasons, and many consider that poor outcomes are produced 'elsewhere.' These findings have significant implications for how HPs talk with parents about clitoral size and how they conceptualise care plans.

The research participants might have felt under pressure to position themselves as HPs who interrogate childhood genital surgery. Therefore, there may have been some selection bias in that only those HPs who questioned elective medical interventions came forward to be interviewed. With this limitation in mind, these HPs understood clitoral surgery on minors to be controversial. This potentially reflects the cultural context in the UK and Scandinavia and may not be generalisable to other locations globally. While a number of strategies for managing the dilemmas could be identified in the interview transcripts, these were often contradictory and could compound HPs' difficulties and confuse families.

Given the historical and ongoing debates about clitoral surgery, the lack of coherence is understandable. Childhood surgery has been standard practice for decades, leaving little scope for comparative research. It is uncertain to what extent the difficulties highlighted by empirical research and survivor stories ${ }^{10-14}$ are influenced by the imperfect results of surgery, other aspects of DSD conditions, poor psychological care, diminished family functioning or a combination of these and perhaps some other factors. HPs advise parents on clitoral surgery under conditions of uncertainty, with no more to guide them than a patchy and rapidly changing surgical literature, survivor stories in the grey literature, human rights challenges, and their personal values and assumptions about the gendered contexts in which children develop. Future research with families who decline clitoral surgery for their child may provide more insight about how the parents or surrogates talk about bodies and bodily differences with their children. This type of research can be helpful for HPs and for parents who have to make difficult decisions for the child.

Our interviewees struggled to reconcile their new knowledge with the incumbent norm-based assumptions. They were clear about the non-linear relationship between anatomy and psychology; they knew that clitoris size did not always predict the scale of individuals' reactions or their wishes regarding surgery. They were simultaneously surprised and even shocked by the unproblematic reactions of those parents and patients who were 'not bothered' by a larger clitoris. A psychologist, for example, described a mother who felt no stigmatisation at all about her daughter's clitoral difference and who apparently said, 'My little daughter can run around naked ... [on the beach] with her big clitoris, I don't mind and no one else should mind either...' (P37). Even so, the psychologist described the mother's tacit acceptance as 'extreme' and lamented that clitoral enlargement could only be tolerated 'in another world.'

Parents and patients opting out of clitoral surgery do not live in another world but the current one, where clinical specialists and care advocates have already produced detailed guides for talking to parents about their child 
with genital variations without relying on medical framing. ${ }^{29}$ Mention of active use of these resources was absent, even though they offer a more helpful language with which to create non-surgical care pathways. Until other expertly and confidently formulated care options become available, many parents do not have a genuine choice. ${ }^{39}$ Surgery may be a high-risk strategy involving multiple hospital visits, regular anatomical inspections and repeat genital operations, but it remains compelling so long as it is the only established treatment pathway. According to the current transcripts, it is the only one articulated.

Ethically and psychosocially informed alternatives require HPs to question the norm-based assumptions, whose salience in the present data begs explaining. DSD care has historically been located in acute medicine, where the dimorphic language of normality and abnormality is integral to a curative model. Such a care model may render normalising interventions inevitable. The acute medical culture may therefore not be the most adept at approaching medically benign genital variations or at fostering the use of richer, more inclusive language ${ }^{29}$ with which to talk and think about diversity of genital anatomy and function.

Wherever DSD care is located in future, the social motivation that underpins clitoral surgery renders two questions inevitable. First, does surgery deliver the projected long-term psychosocial outcomes? Second, is there a less invasive, lower risk and more reversible way than surgery to realise the same outcomes? Instead of being saddled by the first, more familiar question, today's clinicians could switch to the second question. If its answer is 'yes', then the first question is superfluous.

\section{CONCLUSION}

HPs engaged with new knowledge that questioned childhood clitoral surgery but also recycled familiar assumptions that used to be accepted as the rationale for surgery. Their struggles to integrate the conflicting ideas were reflected in the contradictory ways of talking about clitoral surgery and a lack of reference to other care options. The current findings point to a risk of DSD experts working in a silo, unaware of social changes that are afoot, even as some patients and families are beginning to report unproblematic reactions to clitoral differences. In order to translate their broad wish to limit the practice of clitoral surgery, HPs will need to question social norms in the same way that some service users already do. This means adopting a more inclusive language to talk and think about genital differences and formulating alternative interventions to address the psychosocial concerns that surgery is purported to address.

\section{Public and patient involvement}

This study involved HPs rather than patients. A number of research plans were discussed during multiple conversations over a 15-month period and involving the paediatric-adolescent-adult DSD services at Great Ormond Street Hospital and University College London Hospitals in the UK. The eventual research programme was based on the comments and feedback from the large multidisciplinary teams, literature reviews and ethical considerations. The analysis was presented to the teams above before the manuscript was finalised and submitted.

Acknowledgements We are grateful to all 32 health professionals for their participation.

Contributors All listed authors meet authorship criteria and no others meeting the criteria have been omitted: L-ML contributed to the study design, recruited participants, analysed the data and wrote the paper. $\mathrm{PH}$ contributed to the study design and development of the manuscript. SC and TL contributed to the study protocol and development of the manuscript. KR conceptualised the study, recruited participants, collected and analysed the data and wrote the paper. All authors had full access to the data and take responsibility for the integrity of the data and the accuracy of the data analysis.

Funding Fieldwork costs of the last author were covered by the Department of Psychology, University of Oslo, Norway.

Competing interests None declared.

Patient consent for publication Not required.

Ethics approval The study was approved by NHS National Research Ethics Service (reference: 11/L0/0384) and University of Surrey Ethics Committee (reference: EC/2011/68/FAHS).

Provenance and peer review Not commissioned; externally peer reviewed.

Data sharing statement Unpublished data are not available to anyone outside the research team due to the sensitivity of the transcripts.

Open access This is an open access article distributed in accordance with the Creative Commons Attribution Non Commercial (CC BY-NC 4.0) license, which permits others to distribute, remix, adapt, build upon this work non-commercially, and license their derivative works on different terms, provided the original work is properly cited, appropriate credit is given, any changes made indicated, and the use is non-commercial. See: http://creativecommons.org/licenses/by-nc/4.0/.

\section{REFERENCES}

1. Liao L-M, Roen K. Intersex/DSD post-Chicago: new developments and challenges for psychologists. Psychology \& Sexuality 2014;5:1-4

2. Lee PA, Houk CP, Ahmed SF, et al. Consensus Statement on Management of Intersex Disorders. Pediatrics 2006;118:e488-e500.

3. Meyer-Bahlburg HF, Baratz Dalke K, Berenbaum SA, et al. Gender Assignment, Reassignment and Outcome in Disorders of Sex Development: Update of the 2005 Consensus Conference. Horm Res Paediatr 2016;85:112-8.

4. Michala L, Liao LM, Wood D, et al. Practice changes in childhood surgery for ambiguous genitalia? J Pediatr Urol 2014;10:934-9.

5. Crissman HP, Warner L, Gardner M, et al. Children with disorders of sex development: A qualitative study of early parental experience. Int J Pediatr Endocrinol 2011;2011:10.

6. Dayner JE, Lee PA, Houk CP. Medical treatment of intersex: parental perspectives. J Urol 2004;172:1762-5.

7. Rolston AM, Gardner M, Vilain E, et al. Parental Reports of Stigma Associated with Child's Disorder of Sex Development. Int J Endocrinol 2015;2015:1-15.

8. Sanders C, Carter B, Goodacre L. Parents' narratives about their experiences of their child's reconstructive genital surgeries for ambiguous genitalia. J Clin Nurs 2008;17:3187-95.

9. Jesus LE. Feminizing genitoplasties: Where are we now? J Pediatr Urol 2018;14:407-15.

10. Creighton SM, Minto CL, Steele SJ. Objective cosmetic and anatomical outcomes at adolescence of feminising surgery for ambiguous genitalia done in childhood. Lancet 2001;358:124-5.

11. Minto CL, Liao LM, Woodhouse CR, et al. The effect of clitoral surgery on sexual outcome in individuals who have intersex conditions with ambiguous genitalia: a cross-sectional study. Lancet 2003;361:1252-7. 
12. Crouch NS, Liao LM, Woodhouse CR, et al. Sexual function and genital sensitivity following feminizing genitoplasty for congenital adrenal hyperplasia. J Urol 2008;179:634-8.

13. Köhler B, Kleinemeier E, Lux A, et al. Satisfaction with genital surgery and sexual life of adults with XY disorders of sex development: results from the German clinical evaluation study. J Clin Endocrinol Metab 2012:97:577-88.

14. Davis G, Feder E, eds. Narrative symposium: Intersex. Narrative Inquiry in Bioethics. , 2015:5, 87-125.

15. Pippi Salle JL, Braga LP, Macedo N, et al. Corporeal sparing dismembered clitoroplasty: an alternative technique for feminizing genitoplasty. J Urol 2007;178(4 Pt 2):1796-801.

16. Hurwitz RS. Feminizing surgery for disorders of sex development: evolution, complications, and outcomes. Curr Urol Rep 2011:12:166-72.

17. Pasterski V, Prentice P, Hughes IA. Consequences of the Chicago consensus on disorders of sex development (DSD): current practices in Europe. Arch Dis Child 2010;95:618-23.

18. Ellens REH, Bakula DM, Mullins AJ, et al. Psychological Adjustment of Parents of Children Born with Atypical Genitalia 1 Year after Genitoplasty. J Urol 2017;198:914-20.

19. Human Rights Watch. "I Want to Be Like Nature Made Me", Medically Unnecessary Surgeries on Intersex Children in the US. 2017 https://www.hrw.org/sites/default/files/report_pdf/ lgbtintersex0717_web_0.pdf. 978-1-6231-35027.

20 Council of Europe Parliamentary Assembly. Resolution 1952: Children's right to physical integrity. $2013 \mathrm{http} / / / w w w . a s s e m b l y . c o e$. int/nw/xml/ XRef/ Xref-XML2HTMLen.asp?fileid=20174\&lang=en (accessed 31 May 2019).

21. Mendez JE. Report of the special rapporteur on torture, and other cruel, inhuman and degrading punishment. 22nd Session of the UN Human Rights Council. A/HRC/22/53. 2013. http://www.ohchr.org/ Documents/HRBodies/HRCouncil/RegularSession/Session22/A. HRC.22.53 English.pdf (accessed 31 May 2019).

22. Malta. Gender Expression and Sex Characteristics Act. 2015 http:// justiceservices.gov.mt/ (accessed 31 May 2019)

23. The European Union Fundamental Rights Agency. The fundamental rights situation of intersex people. Vienna: FRA - European Union Agency For Fundamental Rights. 2015 http://fra.europa.eu/sites/ default/files/fra-2015-focus-04-intersex.pdf (accessed 31 May 2019).

24. Roen K. Intersex or Diverse Sex Development: Critical Review of Psychosocial Health Care Research and Indications for Practice. The Journal of Sex Research 2019;56(4-5):511-28.
25. Suen LJ, Huang HM, Lee HH. [A comparison of convenience sampling and purposive sampling]. Hu Li Za Zhi 2014;61:105-11.

26. Braun V, Clarke V, Terry G, Analysis T, In Rohleder P, Lyons A, et al. eds. Qualitative Research in Clinical and Health Psychology. Basingstoke: Palgrave MacMillan, 2014:pp95-113.

27. Karkazis K, Tamar-Mattis A, Kon AA. Genital surgery for disorders of sex development: implementing a shared decision-making approach. J Pediatr Endocrinol Metab 2010;23:789-805.

28. Tamar-Mattis A, Baratz A, Baratz Dalke K, et al. Emotionally and cognitively informed consent for clinical care for differences of sex development. Psychology \& Sexuality 2014;5:44-55.

29. Accord Alliance. dsdguidelines.org. 2006 (accessed 31 May 2019).

30. Bougnères $\mathrm{P}$, Bouvattier $\mathrm{C}$, Cartigny $\mathrm{M}$, et al. Deferring surgical treatment of ambiguous genitalia into adolescence in girls with 21-hydroxylase deficiency: a feasibility study. Int J Pediatr Endocrinol 2017;2017.

31. Kessler SJ. The Medical Construction of Gender: Case Management of Intersexed Infants. Signs 1990;16:3-26.

32. Alpern AN, Gardner M, Kogan B, et al. Development of HealthRelated Quality of Life Instruments for Young Children With Disorders of Sex Development (DSD) and Their Parents. J Pediatr Psychol 2017;42:544-58.

33. Lundberg $\mathrm{T}$, Lindström $\mathrm{A}$, Roen $\mathrm{K}$, et al. From Knowing Nothing to Knowing What, How and Now: Parents' Experiences of Caring for their Children With Congenital Adrenal Hyperplasia. J Pediatr Psychol 2017:42: 10.1093/jpepsy/jsw001: 520-9.

34. Liao L-M, Green H, Creighton SM, et al. Service users' experiences of obtaining and giving information about disorders of sex development. Br J Obstetr Gynaecol 2010;117:193-9.

35. Houk CP, Lee PA. Approach to assigning gender in 46,XX congenital adrenal hyperplasia with male external genitalia: replacing dogmatism with pragmatism. J Clin Endocrinol Metab 2010;95:4501-8.

36. Baskin LS, Erol A, Li YW, et al. Anatomical studies of the human clitoris. J Urol 1999;162:1015-20.

37. Chase C. Surgical progress is not the answer to intersexuality. J Clin Ethics 1998:9:385-92.

38. Boyse KL, Gardner M, Marvicsin DJ, et al. "It was an overwhelming thing": parents' needs after infant diagnosis with congenital adrenal hyperplasia. J Pediatr Nurs 2014;29:436-41.

39. Liao LM, Wood D, Creighton SM. Parental choice on normalising cosmetic genital surgery: Between a rock and a hard place. BMJ 2015;351:h5124. 